
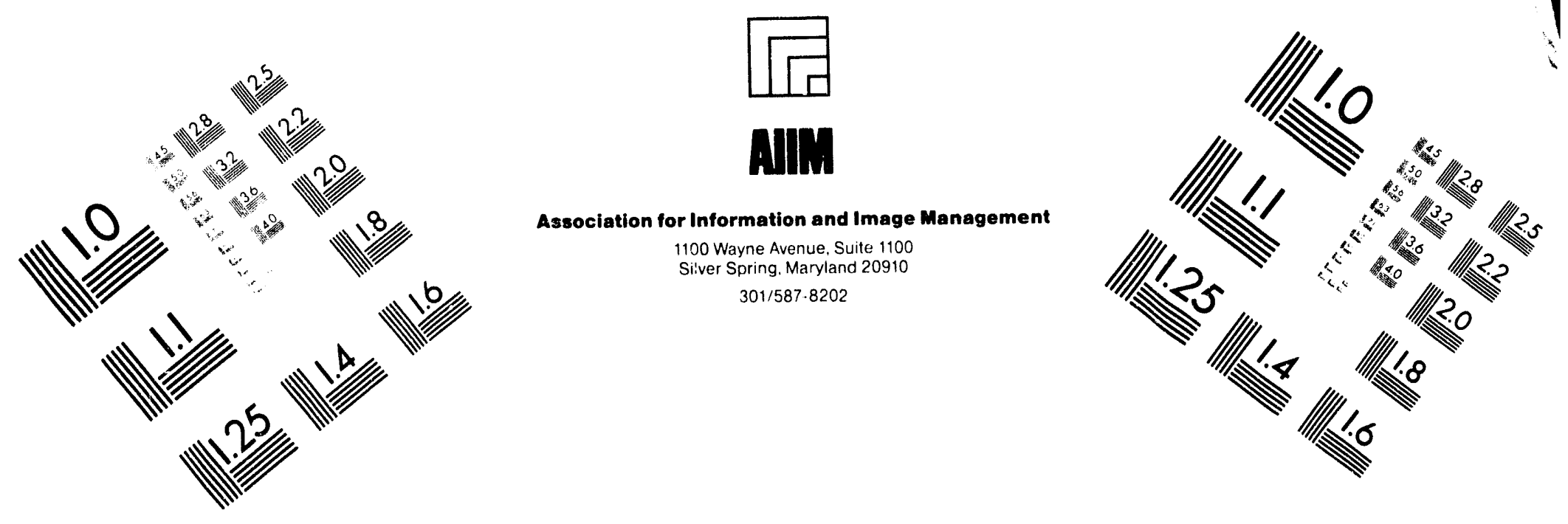

Centimeter

$\begin{array}{llllllllllllllll}1 & 2 & 3 & 4 & 5 & 6 & 7 & 8 & 9 & 10 & 11 & 12 & 13 & 14 & 15 & \mathrm{~mm}\end{array}$

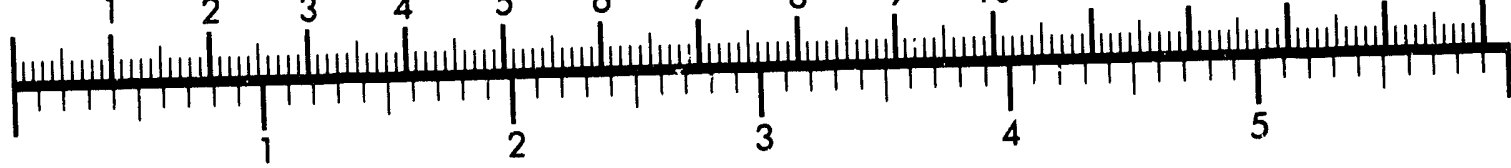
Inches
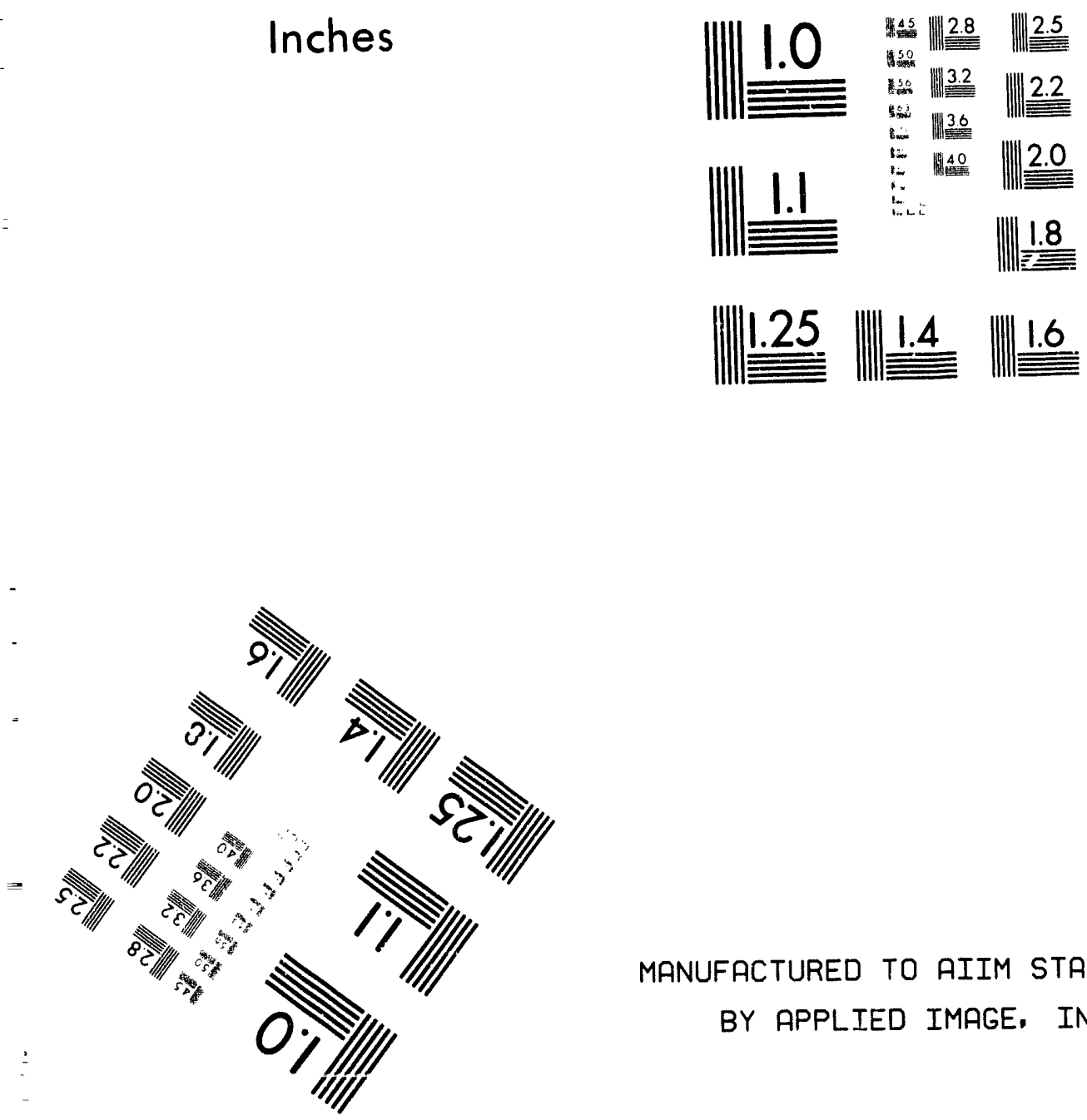

MANUFACTURED TO AIIM STANDARDS BY APPLIED IMAGE, INC.

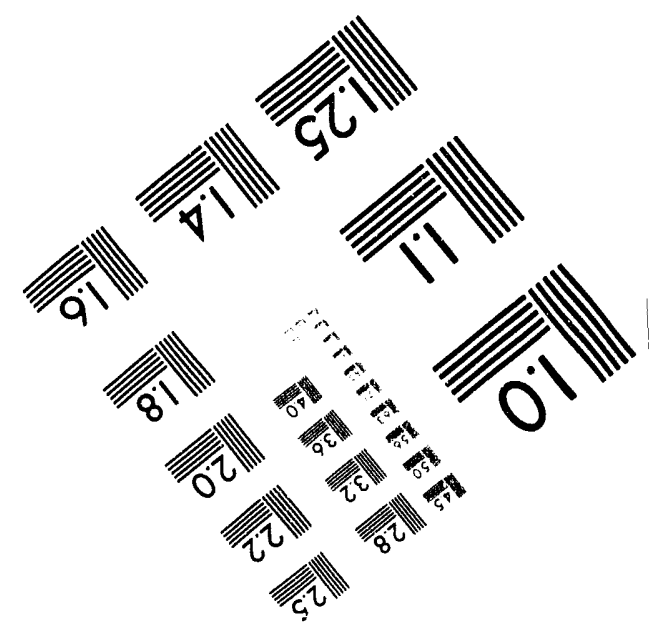



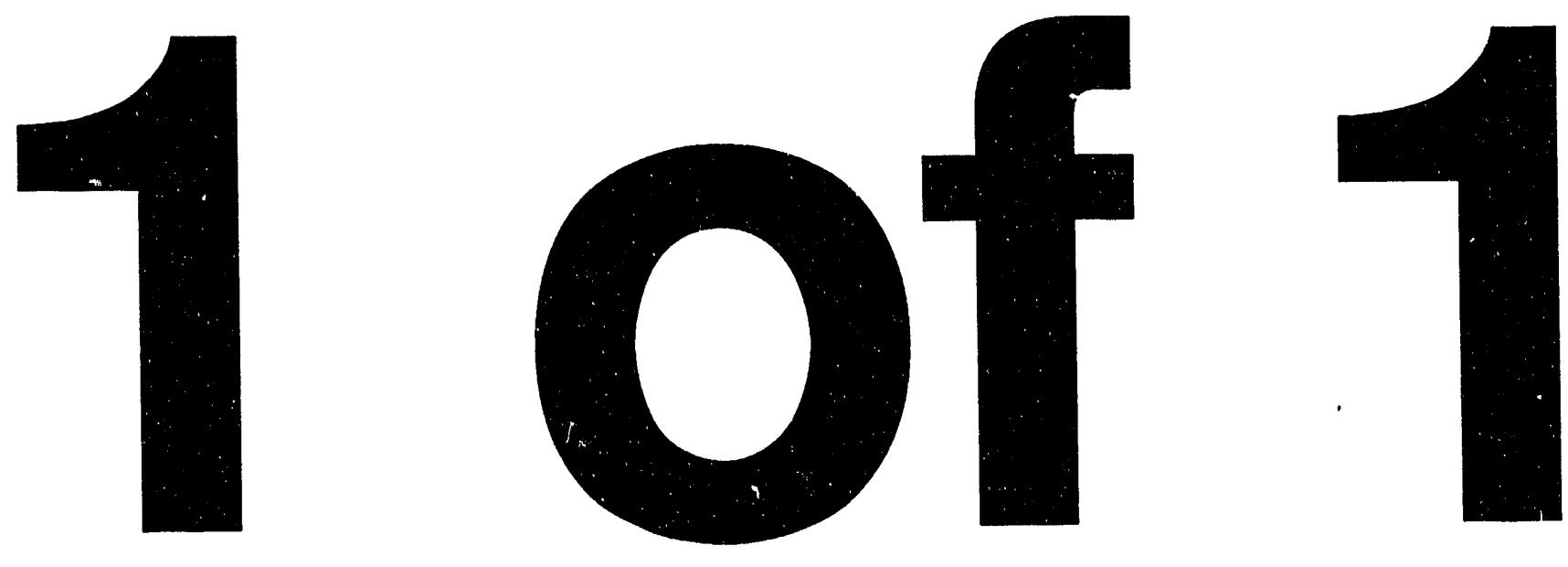


\title{
ALTERNATIVES FOR METAL HYDRIDE STORAGE BED HEATING AND COOLING (U)
}

\author{
by J. R. Knight
}

Westinghouse Savannah River Company

Savannah River Site

Aiken, South Carolina 29808

Other Authors: $\mathrm{MA}$

This paper was prepared in connection with work done under Contract No. DE-AC09-89SR18035 with the U. S. Department of Energy. By acceptance of this paper, the publisher and/or recipient acknowledges the U. S. Government's right to retain a nonexclusive, royalty-free license in and to any copyright covering this paper, along with the right to reproduce and to authorize others to reproduce all or part of the copyrighted paper.

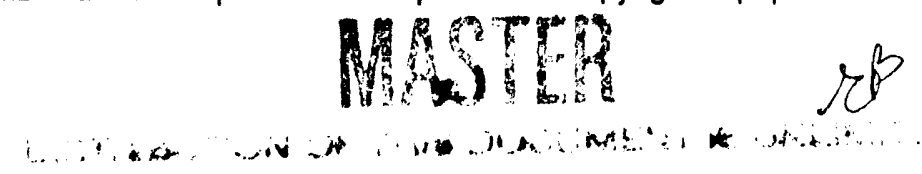




\section{DISCLAIMER}

This report was prepared as an account of work sponsored by an agency of the United States Government. Neither the United States Government nor any agency thereof, nor any of their employees, makes any warranty, express or implied, or assumes any legal liability or responsibility for the accuracy, completeness, or usefulness of any information, apparatus, produc. or process disclosed, or represents that its use would not infringe privately v vned rights. Reference herein to any specific commercial product, process, or service by trade name, trademark, manufacturer, or otherwise does not necessarily constitute or imply its endorsement, recommendation, or favoring by the United States Government or any agency thereof. The views and opinions of authors expressed herein do not necessarily state or reflect those of the United States Government or any agency thereof.

This report has been reproduced directly from the best available copy.

Available to DOE and DOE contractors from the Office of Scientific and Technical Information, P. O. Box 62, Oak Ridge, TN 37831; prices available from (615) $576-8401$.

Available to the public from the National Technical Information Service, U. S. Department of Commerce, 5285 Port Royal Rd., Springfield, VA 22161. 


\author{
Keywords: Replacement Tritium Facility \\ Acooumtability \\ Hydrogen Isotopes \\ Hydrogen Storage \\ Nitrogen
}

Retention: 20 years

October 4, 1991

TO:

J.R. Knight, 773-A

FROM:

I. A. Fisher, 773-A

F B. Ramirez, 773-A

J.E. Koonce, 233-8H

D.E. Ward, $233-8 \mathrm{H}$

L.K. Houng, 773-A

M. Weimer, New South

W. Berkebile, 707-44B

S.T. French, $707-46 B$

Team Co-Leader

Team Co-Leader

Team Member

Team Member

Team Member

Team Member

Team Member

Team Member

\title{
ALTERNATIVES FOR METAL HYDRIDE STORAGE BED HEATING AND COOLING (U)
}

\section{INTRODUCTION}

Tritium PMT and Systems Engineering (SE) personnel requested an investigation of altemative methods for heating and cooling metal hydride storage beds. This request evolves from concerns associated with the equipment required and the operability and maintainability of the Replacement Tritium Facility (RTF) recirculating, pressurized nitrogen heating and cooling system. The Replacement Tritium Purification Facility (RTPF) will also use metal hydride storage beds in its operations. Therefore, the development of an improved method for heating and cooling metal hydride storage beds, which addresses the concerns associated with the current RTF method of heating and cooling, is desirable.

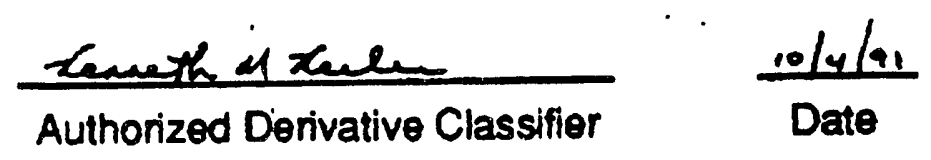


In response to this request a team with representatives from the Savannah River Laboratory (SAL), Tritium PMT, SE, and Bechtel Savannah River incorporated Design Engineering (BSRI-DE) was formed to investigate alternatives for heating and cooling metal hydride storage beds. This report documents the results of the investigation periormed by the team.

\section{SUMMARY}

The reaction of hydrogen isotopes with the storage bed hydride material is exothermic during absorption and endothermic during desorption. Therefore, storage bed operation requires a cooling system to remove heat during absorption. and a heating system to add the heat needed for desorption. Three storage bed designs and their associated methods of heating and cooling and accountability are presented within. The first design is the current RTF nitrogen heating and cooling system. The second design uses natural convection cooling with ambient glove box nitrogen and electrical resistance for heating. This design is referred to as the Naturally Cooled / Electrically Heated (NCEH) design. The third design usess forced convection cooling with ambient glove box nitrogen and electrical resistance for heating. The design is referred to as the Forced Convection Cooled / Electrically Heated (FCCEH) design.

In this report the operation, storage bed design, and equipment required for heating. cooling, and accountability of each design are described. The advantages and disadvantages of each design are listed and discussed. Based on the information presented within, it is recommended that the NCEH design developed by L.K. Heung of SRL be selected for turther development.

\section{REQUIREMENTS FOR RTPF METAL HYDRIDE STORAGE BEDS}

Metal hydride storage beds for the RTPF are to be designed to meet the following requirements supplied by Tritium PMT:

- To be able to discharge hydrogen.isotopes during desorption at pressures up to 1900 torr. 
- To be able to receive hydrogen isotopes at pressures down to 100 torr.

- To be able to store hydrogen isotopes at a safe pressure under loss of cooling conditions.

- To be able to account for the tritium contained in the storage bed.

- To be able to saturate an empty bed with hydrogen isotopes in 6 hours at operating hydrogen isotope supply pressures.

To be able to empty a bed saturated with hydrogen isotopes in 6 hours at operating hydrogen isotope discharge pressures.

\section{BACKGROUND}

In 1984 atternatives for the heating and coolling of all metal hydride applications in the RTF were evaluated1. The altematives investigated at that time included: central recirculating nitrogen heating and cooling, central Dowtherm $J$ (an organic heat transfer liquid) heating and cooling, central Freon cooling with local electric heating, Freon brine cooling with local electric heating, and central Freon heating and cooling. Central recirculating nitrogen heating and cooling for all hydride applications in the RTF was chosen because it possessed the least process hazards of the alternatives investigated.

Unlike the present RTF system, the system for the RTPF would include a system for heating and cooling metal hydride storage beds (i.e. La-Ni-Al based units) and a separate system for heating and cooling the other metal hydride applications (i.e.palladium based units) such as: the Thermal Cycling Absorption Process (TCAP), the inert gas/hydrogen isotope separators (Flow-through Beds), and the palladium sitver diffuser vacuum beds.

The development of separate systems is based on the operating temperatures required for the different units to pertorm their functions. TCAP, the Flow-through Beds, and the diffuser vacuum beds require cooling to temperatures below ambient to perform their desired functions. These units require low temperature operation not to increase process through put, but because of thermodynaric limitations of palladium hydride formation. Metal hydride storage beds however, do not require cooling below ambient temperatures to pertorm their desired function, atthough low 
temperature operation does decrease the time required for the saturation of a storage bed.

Because the time requirement for the saturation of a RTPF storage ted is much less stringent than RTF requirements, cooling below ambient temperatures is not required. Therefore, the two alternatives to the current RTF design presented (NCEH design and FCCEH design) utilize ambient glove box nitrogen for cooling. To decrease the time required for the saturation of a storage bed, both of these atternative designs use LaNi $4.15 \mathrm{Al}_{0.85}$ (LANA 0.85 ) instead of LaNi4.25Al 0.75 (LANA 0.75 ) as the hydride forming alloy. LANA 0.85 has a lower hydrogen isotope absorption pressure than does LANA 0.75 thus providing a greater driving force for absorption. Heating is provided by electric heaters in both the NCEH and FCCEH designs. Heating efficiency is expected to be better than the RTF design in both cases.

\section{DESIGN DESCRIPTIONS}

\section{EXISTING REPLACEMENT TRITIUM FACILITY (RTF) DESIGN}

\section{Metal Hydride Bed Design}

A schematic of a RTF metal hydride storage bed design is shown in Figure 1. The inner vessel consists of a 3 inch diameter schedule 40 pipe. This inner vessel contains the LANA 0.75 hydride forming alloy. Process gases enter and exit through the flanged port at the top of the bed. This port contains a 10 micron sintered stainless steel filter to prevent the hydride material from entering the process. The inner vessel has sixteen $1 / 4$ inch high copper fins brazed on its outer surface to promote heat transier.

The inner vessel is contained within a 4 inch diameter schedule 10 jacket. The jacket has inlet and outlet ports which are connected to the hot and cold nitrogen gas supply. The hot or cold pressurized nitrogen gas passes through the annular region between the outside of the inner vessel and the inside of the jacket. The jacket is insulated to reduce heat loss from the jacket during heating and cooling. 
The inner vessel is directly connected (no valves in between) to an expansion volume. This expansion volume insures that a sate process gas pressure is maintained inside the inner vessel and expansion volume in the event of a loss of cooling from the hot and cold nitrogen system.

\section{Process Description}

The RTF will use recirculating, pressurized nitrogen gas to heat and cool metal hydride storage beds. The pressurized nitrogen is supplied to the beds from a central location where the nitrogen gas is compressed, heated, and cooled. The RTF has two such central nitrogen heating and cooling systems in place to provide process operability in case of down time on one system. Separate piping is used to supply both hot and cold nitrogen to the storage beds as needed from either of the two systems.

The hot and cold nitrogen gas is piped throughout the facility to each of the glove boxes (which provide secondary containment of process gases) requiring hot and cold nitrogen gas. The hot and cold nitrogen gas enters each glove box and is piped to each storage bed. The nitrogen gas flows through the annular region between the inner vessel and the jacket to heat or cool the storage bed as required. After passing through each jacketed storage bed in the glove box, the nitrogen gas is piped back out of each glove box and returned to the central system for compression and heating or cooling.

Tritium accountability is performed by the in-Bed Accoumtability method developed at SRL2. This method measures the temperature rise of a controlled flow rate of ambient nitrogen gas through the annular region between the inner vessel and the jacket under steady state conditions. The temperature rise of the nitrogen gas is due to the heat produced by the decay of tritium to ${ }^{3} \mathrm{He}$. From the temperature rise of the nitrogen gas, the tritium contained in the storage bed is calculated. 
WSRC-RP-91-955

\section{NATURALLY COOLED / ELECTAICALLY HEATED (NCEH) DESIGN}

\section{Metal Hydride Bed Design}

This design was developed by L.K. Heung of SRL ${ }^{3}$ and is illustrated in Figure 2. Heung's design uses a 3 inch diameter schedule 10 or 40 pipe which contains the LANA 0.85 hydride forming alloy. Process gases enter and exit through the flanged port at the top of the bed. This port contains a 10 micron sintered stainless steel fitter to prevent the hydride material from entering the process.

The inner vessel is contained within a 4 inch diameter schedule 10 jacket. The jacket has fins on the outside surface to enhance heat transfer. A port connects the jacket to a helium and vacuum source. Helium and vacuum in the jacket are required to aid heat transfer and provide insulation, respectively. A U-Tube heater well of about 0.5 inch in diameter, with fins on the outside, enters through the jacket and inner vessel at one end. Electric heaters are installed into each leg of the U-Tube to provide heating of the inner vessel. The U-Tube occupies some of the internal volume of the inner vessel, therefore a longer inner vessel is needed to obtain the same storage capacity as the RTF design.

\section{Process Description}

The design uses ambient glove box nitrogen to cool the storage bed and electrical resistance heaters to heat the storage bed. During hydrogen isotope absorption, the storage bed is cooled with the ambient glove box nitrogen by natural convection. The jacket is pressurized with helium to assist in the removal of the absorption heat of reaction. During hydrogen isotope desorption the jacket is evacuated to provide insulation, anc the heaters in the U-tube heater well are tumed on to provide the heat required for the desorption of hydrogen isotopes. The UTube is filled with $\mathrm{He}$ or $\mathrm{N}_{2}$ to enhance heat transter. The power to the heaters will be such that the U-tube temperature will not exceed $=200^{\circ} \mathrm{C}$, thereby avoiding problems associated with tritium permeation through stainless steel. The U-Tube will be designed to accommodate the thermal expansion of stainless steel in the operating temperature range. 
Heung has calculated that this design does not require an expansion tank under loss of cooling conditions (see reference 3). The reason is that the vessel is not insulated. Therefore, the heat from tritium decay is removed by natural convection from the vessel, and the vessel is maintained at a sale pressure.

The method for tritium accountability will be the same as for the RTF design. The jacket is evacuated to provide insulation. Nitrogen gas flows through the intermal Utube at a controlled flow rate and temperature. The measured temperature difference between the inlet and outlet temperature of the nitrogen gas allows the calculation of the tritium contained within the storage bed.

\section{FORCED CONVECTION COOLED / ELECTRICALLY HEATED (FCCEH) DESIGN}

\section{Metal Hydride Bed Design}

A schematic of the FCCEH metal hydride storage bed design is shown in Figure 3. The inner vessel consists of a 3 inch diameter schedule 40 pipe. This inner vessel contains the LANA 0.85 hydride forming alloy. Process gases enter and exit through the flanged port at the top of the bed. This port contains a 10 micron sintered stainless steel filter to prevent the hydride material from entering the process. The inner vessel has fins brazed longitudinally on its outer surface to promote heat transfer. Heater wells are welded longitudinally to the inner vessel between the fins at several locations. The heater wells pass through the jacket at one end. Electric heaters are installed into each well to provide heating of the inner vessel.

The inner vessel is contained within a 5 inch diameter schedule 10 jacket. The jacket has an inlet port which is connected to a blower. The outlet port returns the nitrogen gas to the glove box. The ambient nitrogen gas is forced through the annular region between the outside of the inner vessel and the inside of the jacket by the blower. The jacket is insulated to reduce heat loss from the jacket during heating. A 5 inch diameter jacket is required to increase the annular flow area between the inner vessel and the jacket, which in turn decreases the pressure drop through the annulus, and allows the use of a low pressure blower for cooling. 
As with the present RTF design, an expansion volume is required to insure that a safe process gas pressure is maintained inside the storage bed in the case of a loss of cooling from the blower.

\section{Process Description}

The design uses ambient glove box nitrogen to $c 00$ and electrical resistance heaters to heat the storage beds. During hydrogen isotope absorption, a blower forces ambient glove box nitrogen through the annular region between the inner vessel and the jacket to cool the storage bed by forced convection. During hydrogen isotope desorption the heaters in the heater wells are turned on to provide the heat required for the desorption of hydrogen isotopes. The wells will be exposed to the ambient glove box nitrogen to improve heat transfier between the heaters and the wells. The jacket is insulated to reduce heat loss tromi the jacket during heating.

Tritium accountability is performed by the same In-Bed Accountability method developed for the RTF. The temperature rise of a controlled flow rate of ambient nitrogen gas through the annular region between the inner vessel and the jacket under steady state conditions is measured. From the temperature rise of the nitrogen gas, the tritium contained in the sturage bed is calculated.

\section{ESTIMATED PERFORMANCE}

The main objectives of any design is to provide methods for heating, cooling, and tritium accountability. The estimated efficiency of each design to achieve these objectives is discussed below.

Heatine

For the existing RTF design, the heat required for desorption is provided by the hot nitrogen gas. The existing design will be able to meet the bed desorption time required for RTPF storage beds. 
Both the NCEH and the FCCEH dosigns uso olbctric hoating. Houng has estimated that the NCEH design should have desorption times better than the RTF design and will meet the RTPF storage bed requirements. In the FCCEH design, the number and placement of the heater wells containing electric heaters is flexible. Therefore, the wells and heaters can be designed to achieve the heating rate desired without causing hot spots in the hydride material. Upon optimization of the heater well location and number, the desorption times are estimated to be better than the existing RTF design and will meet the requirement for the RTPF storage beds.

\section{Cooling}

The absorption rates calculated for the three designs are shown in Figure 4. The times required for the saturation of an empty bed for each design are shown in Figure 5.

Figure 5 shows that the RTF design has the fastest bed saturation times. The FCCEH bed saturation times are about twice as long as the RTF design, and the NCEH design bed saturation times are 4-6 times as long as the RTF design. Figure 5 shows that all three designs meet the absorption times required for RTPF storage beds.

\section{In-BedAccountability}

\section{Existing Design}

In-Bed Accountability will be accomplished by flowing ambient nitrogen gas through the annular region between the inner vessel and the .jacket at steady state and measuring the temperature rise. The existing method for In-Bed Accountability provides the baseline to which the other two designs can be compered. This method is new to tritium processing at SRS, and provides. the most accurate method currently available for the accountability of tritium in hydride beds. 


\section{NCEH Design}

In-Bed Accountability will be accomplished by flowing nitrogen gas through the UTube heater well, which is inside the inner hydride vessel, and measuring the temperature rise. During accountability the jacket will be evacuated to provide insulation. In this design, more of the tritlum decay heat will be transferred to the nitrogen gas for accountability purposes as compared to the current RTF design. Less heat will be lost through the insulated jacket, and less heat will be lost to conduction through stainless ste日l materials. This design is estimated to provide more accurate tritium accourtability than the RTF design, as well as require less time to achieve steady state conditions required to perform tritium accountablity.

FCCEH Desiọn

In-Bed Accountability will be accomplished by flowing nitrogen gas through the annular region between the inner vessel and the jacket and measuring the temperature rise. Since this design utilizes a 5 inch jacket (instead of the 4 inch jacket used in the RTF design), more of the tritium decay heat will be lost through the insulated jacket because of the increased heat transfer area. Therefore, the accountability of tritium is estimated to be slightly less accurate then the RTF design. The time required to achieve steady state conditions required for tittlum accountability is estimated to be slightly longer.

\section{DISCUSSION OF THE ALTERNATIVES}

All three designs presented in this document can meet the requirements listed earlier for RTPF storage beds. However, each design has advantages and disadvantages associated with its implementation. These advantages and disadvantages are described below. 
WSRC-RP-91-955

\section{Existing Desion}

\section{Advantages}

The existing design has the fastest absorption rates. The existing design also has a method of In-Bed Accountability developed specifically for the design geometry. There is also a significant amount of operating experience with this type of heating and cooling system and bed design in the Advanced Hydride Laboratory (AHL) at SRL.

\section{Disactrantages}

Disadvantages associated with the existing RTF system are:

- The need for a centralized nitrogen cooling, heating, and circ.ation system.

- Maintenance of the centrafized nitrogen cooling, heating, and circulation equipment.

- The extensive piping required to deliver the nitrogen to the glove boxes.

- The potential for the contamination of the hot and cold nitrogen which is recirculated outside of the glove boxes.

- The need for difficult to instai. and maintain insulation on each storage vessel. (The insulation must be maintained to provide accurate tritium accountability.)

- The need for a large expansion volume on each bed which occupies valuable glove box space.

\section{NCEH Desion}

Advantages

The advantages of the NCEH design include:

- The elimination of the need for an external centralized nitrogen cooling, heating, and circulation system. 
- The hydride storage vessel is inherently safe under loss of cooling conditions and theretore does not require an expension tank.

- Glove box space required will be dećreased because of the absence of an expansion tank.

- Potentialiy improved In-Bed Accountability of tritum.

\section{Disadvantages}

The disactvantages of the NCEH design include:

- Slower absorption rates than the existing RTF design.

- A source of vacuum and pressurized hellum is required.

- A longer inner vessel will be required, due to the volume ocaupled by the $U$-tube present in the inner vessel.

\section{ECCEH Desion}

Advantages

The advantages include:

- The elimination of the need for an extemal centralized nitrogen refrigeration, heating, and circulation system.

- The absorption rate is faster than the NCEH design because forced convection cooling is provided.

Disaovantages

The disadvantages include:

- Slower absorption rates than the existing RTF design.

- The need for difficult to install and maintain insulation on each storage vessel. (The insulation must be maintained to provide accurate tritum accountability.) 
- The need for a large expansion volume on each bed which occupies valuable glove box space.

- A blower is required, which requires additional glove box space and increased maintenance.

\section{CONCLUSIONS AND RECOMMENDATIONS}

Since the absorption times requirad for the RTPF storage beds are much less stringent than the RTF requirements, ambient glove box cooling, as proposed for the NCEH and FCCEH designs, can be used while still meeting the RTPF absorption time requirement. Because the use of ambient glove box nitrogen cooling eliminates the need for cooling equipment external to the glove boxes, the major disadvantages of the existing RTF design listed above are avoided. Therefore, the current RTF method of heating and cooling storage beds should not be considered as a method for heating and cooling RTPF storage beds.

The NCEH design meets all the requirements defined for RTPF storage beds, occupies less giove box space, does not require insulation, an expansion tank or blower, and provides a potentially more accurate method of tritium accountability. Therefore, the NCEH design is preferred over the FCCEH design for further development and potential implementation for heating and cooling RTPF storage beds.

It is therefore recommended that the NCEH design be developed to provide a method for heating, cooling, and tritium accountability of RTPF storage beds. In order to insure that the conceptual design is successfully developed and implemented, it is recommended that a full size experimental bed be fabricated and its performance be tested with protium and simulated tritium decay heat at SRL. SRL currently has a facility in place to perform these tests. The evaluation of the . experimental bed should address the following:

- Hydrogen isotope absorption rates as functions of the hydrogen supply pressure and the helium pressure in the jacket.

- Hydrogen isotope desorption rates as a function of electric heater power.

- Accountability measurements with hydrogen and simulated tritium decay heat. 
WSRC-RP-91-955

\section{REFERENCES}

1. RTPF Heating/Cooling Alernatives Meeting Minutes, July 18, 1991, SRL-HTS-91-189; and 233-H Refrigeration and H\&V Systems Review, Nov. 2, 1984, M. Censurato.

2. J.E. Klein, Results of SRL In-Bed Accountablity Development Program (U), WSRC-TR-91-180, May 6, 1991.

3. L.K. Heung, New Tritium Storage Bed Design Concept, SRL-HTS-91-0164, Sept. 10, 1991. 


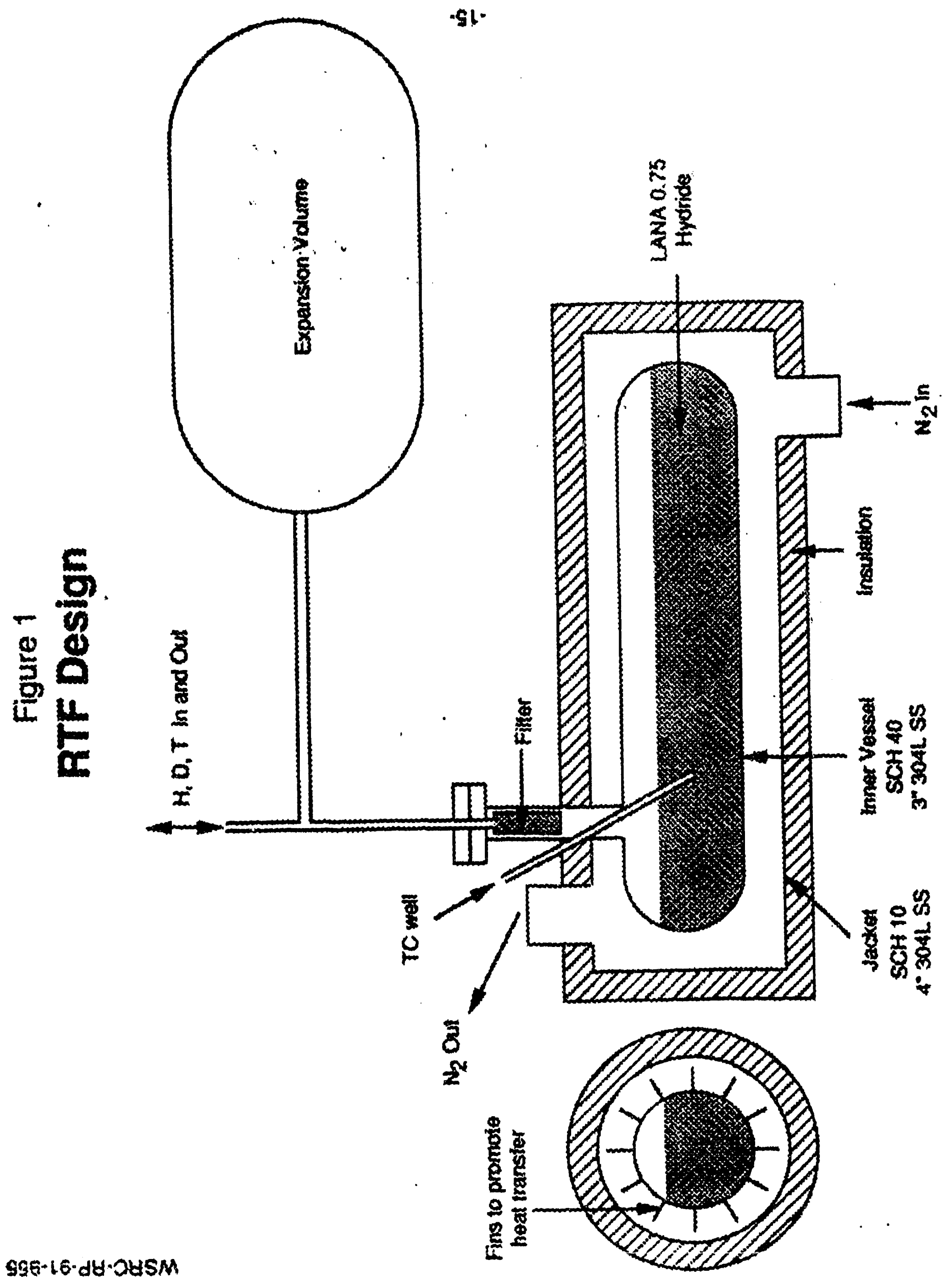



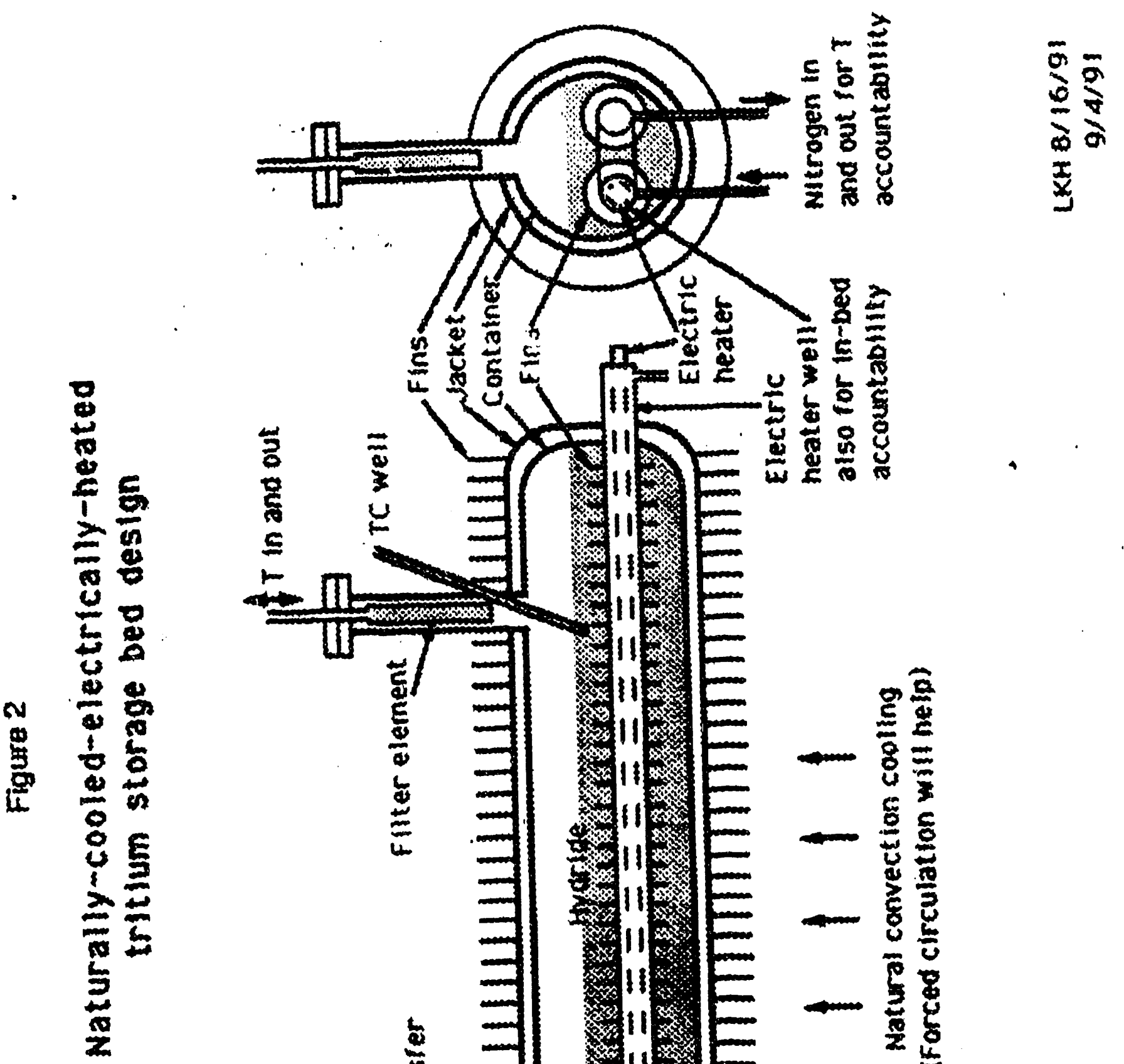


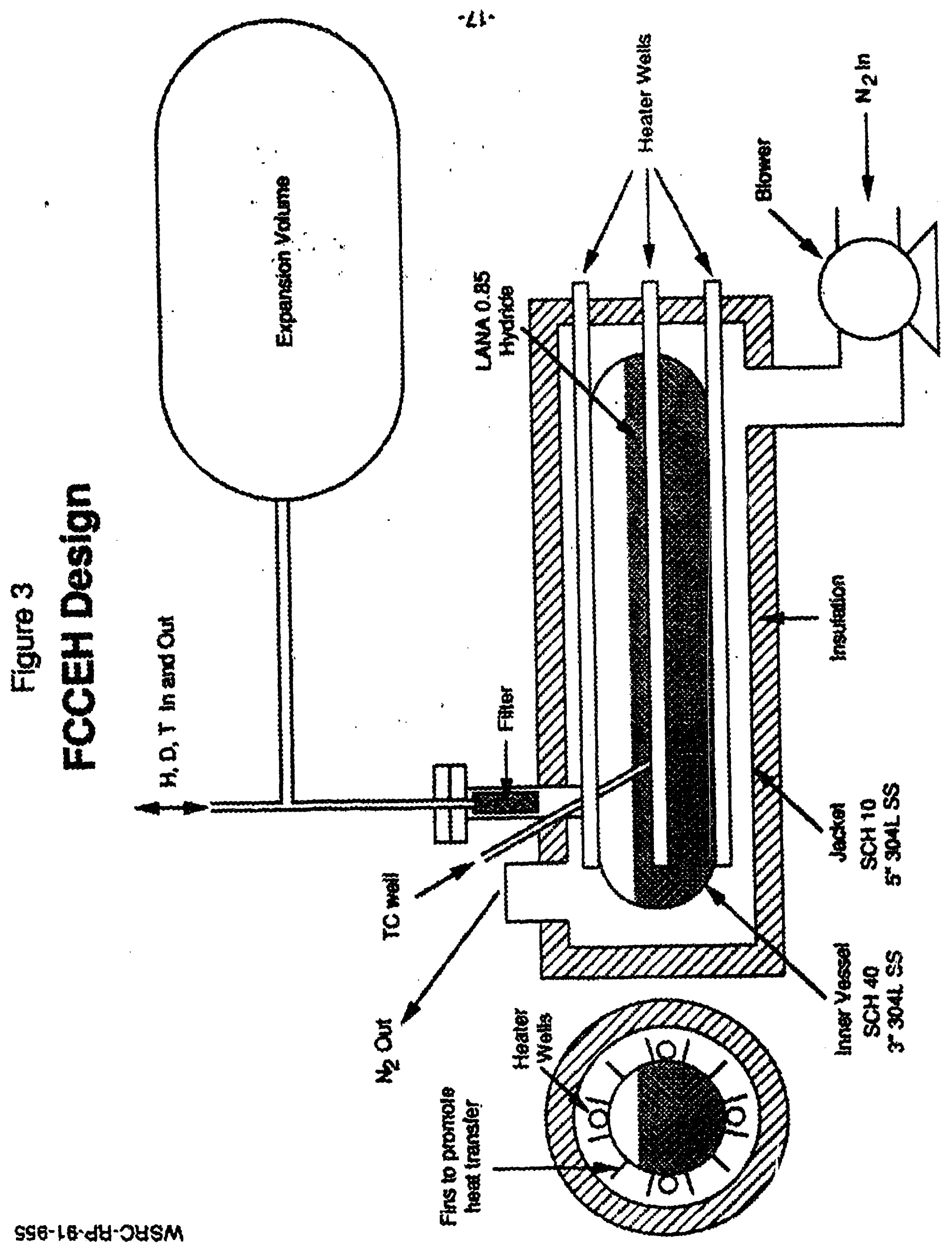




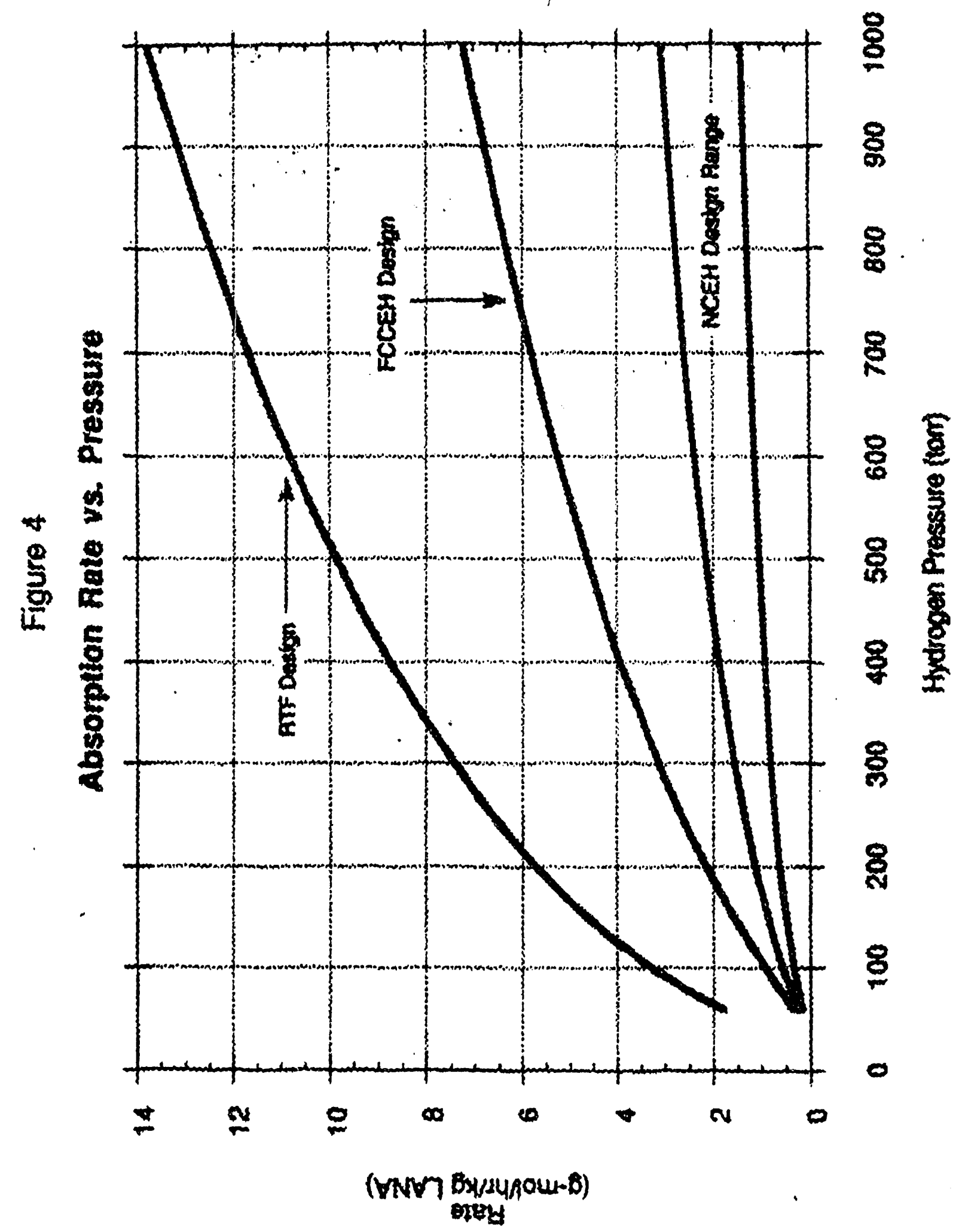

$\$ 96-16-d y-085 M$ 


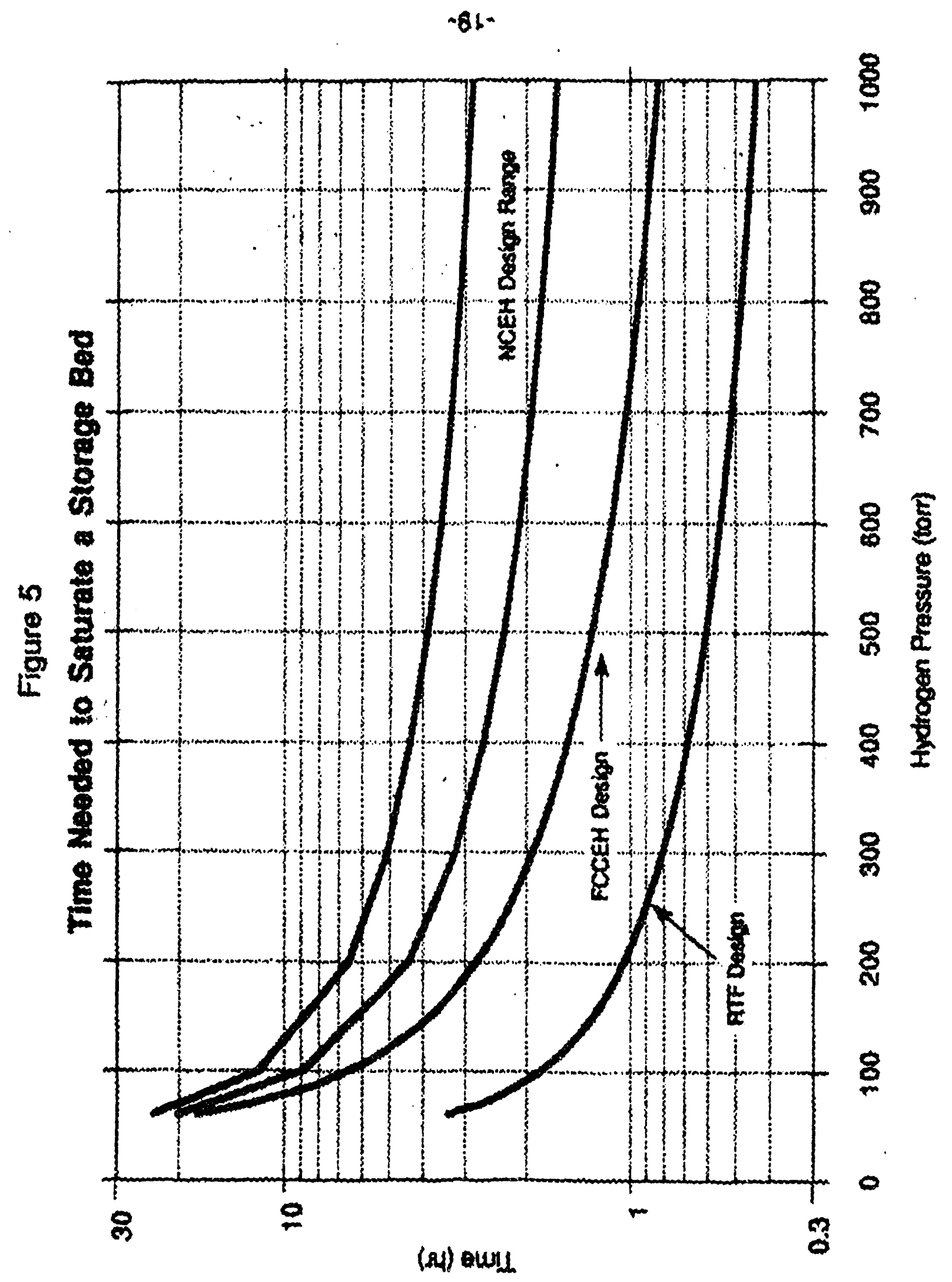

$996-16-d 4-045 M$ 

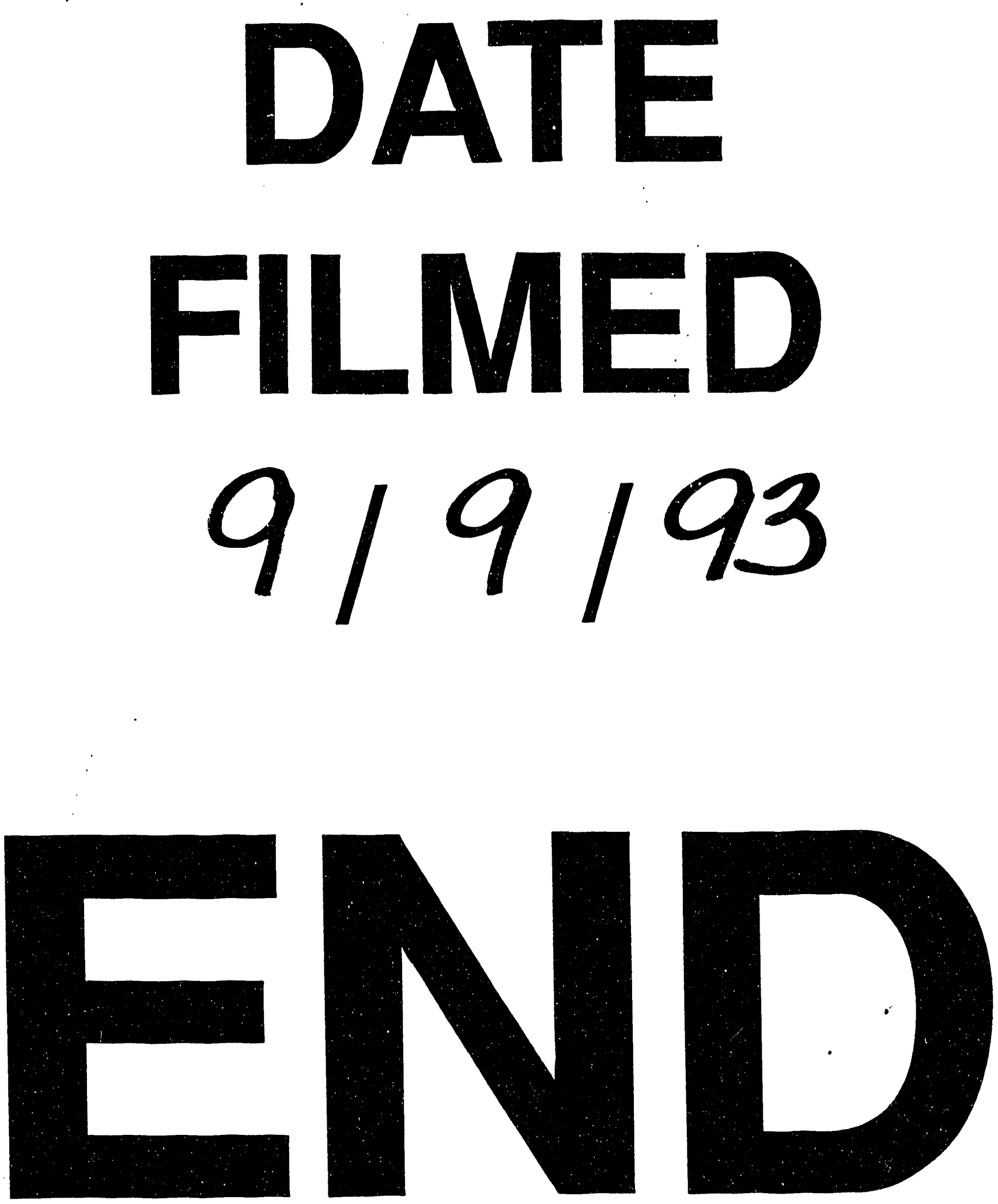
